\title{
ANALISIS SAHABAT SENSUS PADA SENSUS PENDUDUK ONLINE 2020 DI WILAYAH KALIMANTAN BARAT
}

\author{
Naomi Nessyana Debataraja1) \\ Fitri Sulastri2) \\ Ellen Valensia1) \\ 1)Program Studi Statistika, FMIPA Universitas Tanjungpura \\ 2)Badan Pusat Statistik Provinsi Kalimantan Barat \\ e-mail: naominessyana@math.untan.ac.id
}

\begin{abstract}
Implementation of 2020 census of Indonesian Population is the government's first step in realizing One Indonesian Population Data. The online census of Indonesian population is one of the stages of the 2020 census of Indonesian Population where residents can enter their information independently through the website. In order to increase public participation in 2020 online census of Indonesian population, BPS Collaborates with universities throughout Indonesia, one of which is the Mathematics Department of Tanjungpura University Pontianak as a census friend. This study aims to provide an overview of the publicity of the online census and its responses as well as the obstacles experienced by census friends, to determine the factors that affect the constraints of census friends, and to examine the effect of gender variables on the constraints of census friends. The results of the analysis show that the social media used in the publication of the 2020 online census are Instagram, WhatsApp, Facebook, Telegram, Twitter, and Sestyc. The obstacles experienced by census friends amounted to twelve obstacles. The constraint factor which is formed from the factoring process produces two factors. Besides, it was found that there was no influence between the sexes on the constraints of census friends.
\end{abstract}

Keywords: Indonesian population, census friends, publication, factor analysis

\begin{abstract}
ABSTRAK
Pelaksanaan Sensus Penduduk Indonesia Tahun 2020 merupakan langkah awal pemerintah dalam mewujudkan Satu Data Kependudukan Indonesia. Sensus Penduduk Indonesia secara online merupakan salah satu tahapan dari Sensus Penduduk Indonesia Tahun 2020 dimana penduduk dapat memasukkan informasinya secara mandiri melalui website yang telah disediakan. Dalam rangka meningkatkan partisipasi masyarakat dalam pencacahan penduduk Indonesia secara online tahun 2020, BPS bekerja sama dengan 43 perguruan tinggi di seluruh Indonesia, salah satunya Jurusan Matematika Universitas Tanjungpura Pontianak sebagai sahabat sensus. Penelitian ini bertujuan untuk memberikan gambaran tentang publisitas sensus online beserta tanggapannya serta kendala yang dialami oleh sahabat sensus, menentukan faktor-faktor yang mempengaruhi kendala teman sensus, dan untuk menentukan pengaruh variabel jenis kelamin terhadap kendala tersebut. Hasil analisis menunjukkan bahwa media sosial yang digunakan dalam publikasi sensus online 2020 adalah Instagram, WhatsApp, Facebook, Telegram, Twitter, dan Sestyc. Hambatan yang dialami teman sensus berjumlah dua belas kendala. Faktor kendala yang
\end{abstract}


terbentuk dari proses faktorial menghasilkan dua faktor. Selain itu, tidak ditemukan adanya pengaruh antar jenis kelamin terhadap kendala sahabat sensus.

Kata kunci: penduduk Indonesia, sahabat sensus, publikasi, analisis faktor

Tata Kelola data yang baik merupakan salah satu faktor penting dalam perencanaan pembangunan. Salah satu implementasi perbaikan tata kelola data pemerintah ditandai dengan dikeluarkannya Peraturan Presiden Republik Indonesia Nomor 39 Tahun 2019 tentang Satu Data Indonesia. Berdasarkan peraturan tersebut disampaikan bahwa Satu Data Indonesia merupakan kebijakan tata kelola data pemerintah untuk menghasilkan data yang akurat, mutakhir, terpadu, dan data dipertanggungjawabkan, serta mudah diakses dan dibagipakaikan antar Instansi Pusat dan Instansi Daerah melalui pemenuhan standar data, metadata, interoperabilitas data, dan menggunakan kode referensi dan data induk. Pelaksanaan Sensus Penduduk 2020 (SP 2020) merupakan langkah awal pemerintah dalam mewujudkan Satu Data Kependudukan Indonesia. Berdasarkan Undang-undang Nomor 16 Tahun 1997 tentang Statistik, Sensus penduduk merupakan cara pengumpulan data yang dilakukan melalui pencacahan semua unit populasi diseluruh wilayah Republik Indonesia, kegiatan ini dilakukan untuk memperoleh karakteristik suatu populasi pada saat tertentu. Badan Pusat Statistik (BPS) sebagai lembaga pemerintah non kementerian memiliki wewenang untuk melaksanakan Sensus Penduduk setiap sepuluh tahun sekali. Langkah penting dalam mewujudkan Satu Data Kependudukan Indonesia pada SP 2020 adalah penggunaan data administrasi kependudukan dari Direktorat Jenderal Kependudukan dan Pencatatan Sipil (Ditjen Dukcapil) sebagai basis data yang menjadi dasar untuk dilengkapi pada pelaksanaan SP 2020.

Sensus Penduduk 2020 dilaksanakan dalam dua tahapan, yaitu Sensus Penduduk Online (SP Online) dan Sensus Penduduk Wawancara (Maghfira dan Ridho, 2021). Melalui SP Online, penduduk dapat mengisikan informasinya secara mandiri melalui website sensus.bps.go. id. Pelaksanaan SP Online dimulai dari tanggal 15 Februari sampai dengan 29 Mei 2020. BPS menargetkan $22,9 \%$ atau 18 juta keluarga yang merupakan warga negara Republik Indonesia tercatat melalui SP Online 2020.

Demi meningkatkan partisipasi masyarakat dalam Sensus Penduduk Online 2020, Badan Pusat Statistik (BPS) menjalin kerjasama dan berkoordinasi dengan pihak Perguruan Tinggi seIndonesia; melalui 43 Perguruan Tinggi di Indonesia, salah satunya Jurusan Matematika Universitas Tanjungpura Pontianak sebagai "Sahabat Sensus". Anggota Sahabat Sensus Universitas Tanjungpura terdiri dari dosen dan mahasiswa. Sahabat Sensus berperan dalam mengajak masyarakat untuk mengisi SP Online dengan mempublikasikan SP Online diberbagai media sosial dan membantu masyarakat dalam proses pengisian SP Online. Dalam menjalankan perannya, Sahabat Sensus tidak terlepas dari kendala-kendala tertentu.

Analisis deskriptif memberikan gambaran tingkat publisitas SP Online dan tanggapannya serta kendala yang dialami oleh Sahabat Sensus. Tujuan dari analisis ini adalah untuk menentukan media sosial yang digunakan mahasiswa dalam kegiatan publikasi SP Online beserta jumlah tanggapan yang diterima masing-masing media sosial tersebut menggunakan analisis deskriptif.

Selain itu untuk menentukan faktor yang mempengaruhi kendala Sahabat Sensus digunakan analisis faktor dalam penelitian ini. Hasil dari analisis kendala yang dialami Sahabat Sensus diharapkan dapat membantu dalam menentukan perbaikan yang diperlukan dalam SP Online. 


\section{METODE}

Data yang digunakan dalam penelitian ini merupakan data yang diperoleh dari laporan 102 mahasiswa Jurusan Matematika, Fakultas Matematika dan IImu Pengetahuan Alam, Universitas Tanjungpura yang menjadi sahabat sensus.102 mahasiswa yang selanjutnya disebut sahabat sensus dikelompokkan menjadi 18 kelompok yang ditentukan dengan metode sampling acak sederhana. Sedangkan jumlah kelompok ini didasarkan pada jumlah sahabat sensus dari kelompok dosen yang tersedia. Data ini terdiri dari jenis media sosial yang digunakan dan jumlah tanggapan yang diterima. Penelitian ini dilakukan dengan pengumpulan data kendala-kendala pada kelompok Sahabat Sensus yang selanjutnya digunakan sebagai variabel penelitian. Variabel-variabel tersebut antara lain ketidakpercayaan responden terhadap sensus penduduk online 2020 (K1); gangguan jaringan atau sinyal di daerah pedalaman yang dialami responden dalam mengisi sensus penduduk online 2020 (K2); server sensus penduduk online 2020 sering down (K3); kurangnya kepedulian responden terhadap sensus penduduk online 2020 (K4); Nomor NIK dan KK responden yang tidak terdaftar (K5); kurangnya informasi yang diperoleh masyarakat mengenai sensus penduduk online 2020 (K6); data KK yang belum diperbaharui (K7); ketidakpandaian responden dalam mengoperasikan smartphone (K8); hanya browser tertentu yang dapat mengakses halaman website sensus penduduk online 2020 (K9); tidak semua masyarakat memiliki fasilitas smartphone atau laptop (K10); sahabat sensus tidak dapat mengajak masyarakat dalam mengisi sensus penduduk online secara langsung dikarenakan pandemi Covid-19 (K11); serta pilihan jawaban yang tidak lengkap sehingga membingungkan responden (K12).

Analisis Chi Kuadrat digunakan untuk menentukan apakah jenis kelamin mempengaruhi kendala yang dialami oleh Sahabat Sensus dalam pelaksanaan Sensus Penduduk Online 2020. Chi Kuadrat merupakan metode statistika pengujian hipotesis data diskrit yang mengevaluasi korelasi antar dua variabel dan menentukan apakah variabel tersebut saling berkaitan atau tidak, pada tes keterkaitan, ketika diterapkan populasi suatu objek, maka akan ditentukan apakah subjek tersebut terkait atau tidak (Suharno, Fauzi dan Perdana, 2017).

Menurut Sugiyono (2014), Analisis Chi Kuadrat $\left(\chi^{2}\right)$ satu sampel adalah teknik statistik yang digunakan untuk menguji hipotesis bila dalam populasi terdiri atas dua atau lebih kelas dimana data berbentuk nominal dan sampelnya besar. Atau dengan kata lain pengujian ini untuk menentukan apakah variabel satu memiliki hubungan dengan variabel lainnya. Menurut Hasaniyah (2015), hipotesis yang digunakan dalam Uji Chi Kuadrat adalah sebagai berikut:

$\mathrm{H}_{0}$ : tidak terdapat perbedaan atau pengaruh antara variabel satu dengan variabel lain.

$\mathrm{H}_{1}$ : terdapat perbedaan atau pengaruh antara variabel satu dengan variabel lain.

Nilai Chi-Kuadrat dapat dihitung dengan rumus sebagai berikut (Upomo dan Rini, 2016):

$$
X^{2}=\sum_{i=1}^{r} \sum_{j=1}^{k}\left(\frac{f_{i j}-e_{i j}}{e_{i j}}\right)^{2}
$$

$\chi^{2}$ : Nilai Chi Kuadrat

$f_{i j}$ : Frekuensi yang diamati baris ke-i kolom ke-j dalam penelitian

$e_{i j}$ : Frekuensi yang diharapkan baris ke-i kolom ke-j pada penelitian

$k$ : banyak kolom

$r$ : banyak baris 
Kriteria pengujian untuk menolak $\mathrm{H}_{0}$ jika nilai dari Chi Kuadrat hitung lebih besar dari Chi Kuadrat tabel $\left(\chi_{\text {hitung }}^{2}>\chi_{\text {tabel }}^{2}\right)$ dengan derajat kebebasan yang telah ditetapkan $\left.(d b=(r-1) k-1)\right)$ (Liberna, 2018). Dari nilai-nilai Chi Kuadrat yang diperoleh ditarik kesimpulan berdasarkan hipotesis yang telah ditetapkan. Derajat kebebasan untuk Chi Kuadrat tidak tergantung pada jumlah individu dalam sampel (Sugiyono, 2014). Namun derajat kebebasan bergantung pada jumlah variable dalam penelitian.

Analisis Faktor merupakan metode reduksi data untuk menentukan variabel-variabel baru yang nantinya disebut dengan faktor (Ismail, Siti dan Ruslan, 2013). Jumlah dari faktor ini lebih sedikit dibandingkan dengan jumlah variabel, yang tidak berkorelasi satu sama lainnya. Faktor-faktor tersebut memuat sebanyak mungkin informasi yang terkandung didalam variabel aslinya (Rahman dan Fauziana, 2018). Namun pada penelitian tersebut menggunakan ukuran sampel yang relatif kecil. Ada beberapa asumsi yang harus terpenuhi dalam analisis faktor, yaitu sebagai berikut:

a. Korelasi atau keterkaitan antar variabel harus kuat. Hal ini dapat diketahui dari nilai determinannya yang mendekati nol. Nilai determinan dari matriks korelasi yang elemenelemennya mempunyai matriks identitas akan memiliki nilai determinan sebesar satu (Syahrial $d k k, 2018)$.

b. Indeks perbandingan jarak antara koefisien dengan koefisien korelasi parsialnya secara keseluruhan harus kecil. Hal ini dapat diidentifikasikan dengan nilai Kaiser-Meyer-Olkin (KMO). $\mathrm{KMO}$ adalah salah satu indeks perbandingan jarak antara koefisien korelasi parsialnya secara keseluruhan (Ismowati dan Sulatifah, 2019). Nilai KMO harus $\geq 0,5$ agar analisis faktor dapat dilakukan. Selain dengan KMO juga digunakan Measure of Sampling Adequacy (MSA). Kriteria analisis faktor adalah memiliki nilai MSA $\geq 0,5$. Jika ada variabel yang memiliki nilai MSA $<0,5$ maka variabel tersebut harus dikeluarkan terlebih dahulu (Rahayu dan Mustakim, 2017).

Selanjutnya, Analisis Faktor yang dilakukan untuk menentukan faktor-faktor yang mempengaruhi kendala sahabat sensus dalam SP Online 2020 dilakukan dengan tahapan sebagai berikut (Fitriatien, 2017):

a. Merumuskan kendala-kendala yang dialami oleh Sahabat Sensus.

b. Menyusun matriks korelasi dari kendala Sahabat Sensus untuk menganalisis apakah data kendala tersebut cukup memenuhi syarat didalam analisis faktor.

c. Mengekstraksi faktor kendala tersebut digunakan untuk mereduksi data dari beberapa kendala untuk menghasilkan faktor kendala yang lebih sedikit.

d. Merotasi faktor kendala tersebut agar dapat memperoleh struktur faktor yang lebih sederhana agar mudah diinterpretasikan.

e. Menginterpretasikan faktor kendala yang tersisa untuk mengetahui variabel yang membentuknya.

\section{HASIL DAN PEMBAHASAN}

Dalam menjalankan Aksi Sahabat Sensus, salah satu peran penting Sahabat Sensus adalah mempublikasikan SP Online di berbagai media sosial. Dari data yang diperoleh terdapat 538 kali publikasi yang dilakukan oleh sahabat sensus di berbagai media sosial. Media sosial yang digunakan mahasiswa dalam kegiatan publikasi Sensus Penduduk Online yang disajikan pada Gambar 1.

Berdasarkan Gambar 1, media sosial yang digunakan mahasiswa dalam kegiatan publikasi SP Online adalah Instagram, WhatsApp, Facebook, Telegram, Twitter, dan Sestyc. Instagram 
merupakan media sosial yang paling banyak digunakan untuk publikasi SP Online dengan total sebanyak 220 kali publikasi. Selanjutnya adalah WhatsApp dengan 209 kali publikasi, Facebook dengan 102 kali publikasi, Telegram dengan 4 kali publikasi, Twitter dengan 2 kali publikasi, dan Sestyc dengan jumlah publikasi paling sedikit, yaitu hanya sekali publikasi.

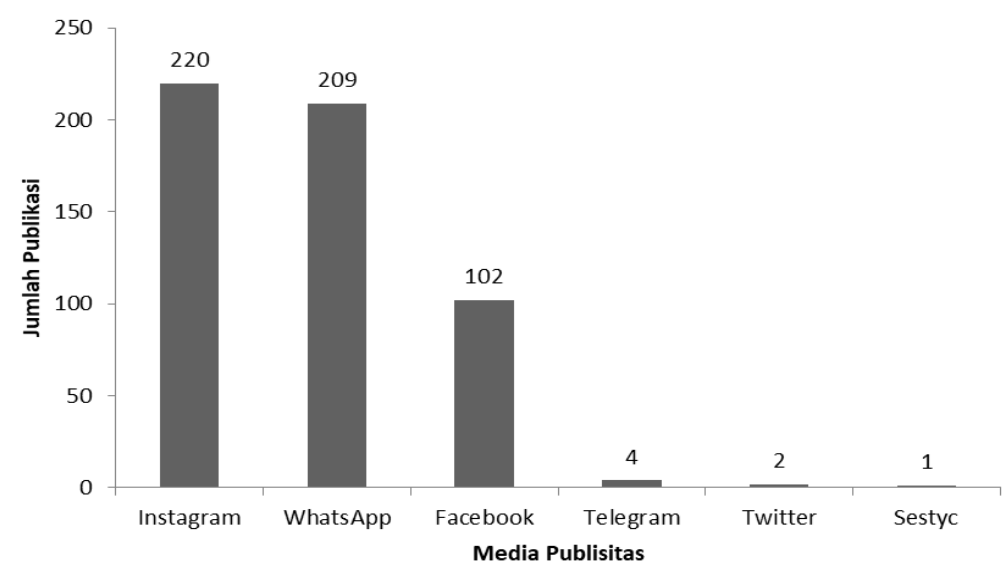

Gambar 1. Media sosial yang digunakan untuk publikasi

Dalam menjalankan perannya, sahabat sensus tidak terlepas dari berbagai kendala yang dihadapi. Analisis Deskriptif yang menggambarkan jumlah kendala yang dialami tiap kelompok sahabat sensus dan jumlah kelompok sahabat sensus di setiap kendala disajikan pada Gambar 2.

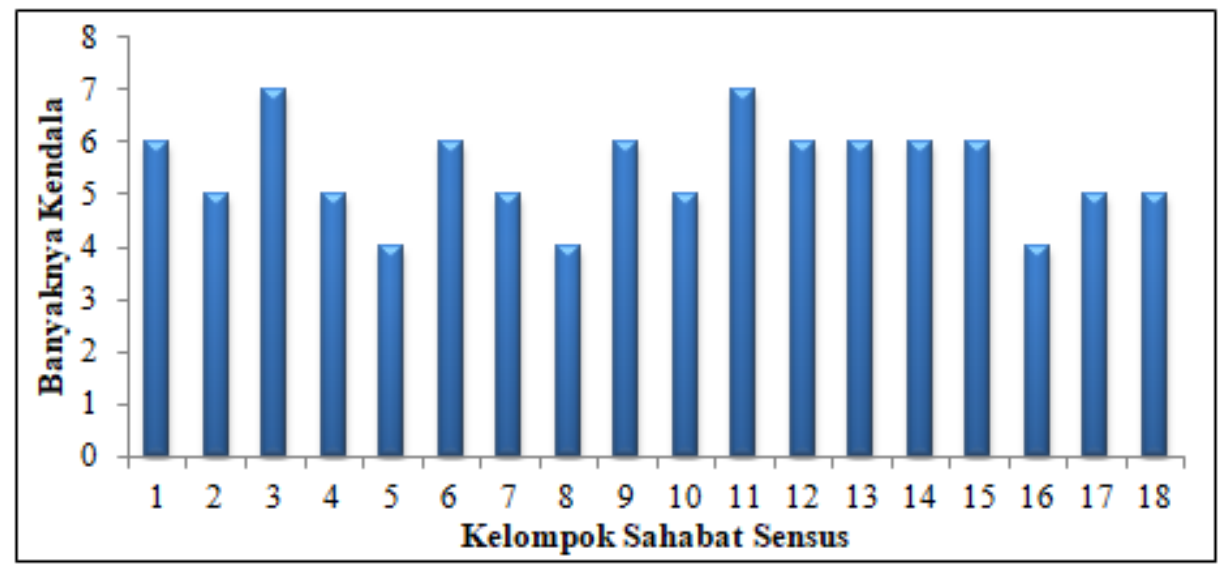

Gambar 2. Jumlah kendala kelompok sahabat sensus

Dari Gambar 2 dapat dilihat bahwa kendala yang dialami kelompok sahabat sensus berjumlah 98 kendala. Masing-masing kelompok sahabat sensus memiliki empat sampai dengan tujuh kendala. Terdapat tiga kelompok yang memiliki kendala paling sedikit, yaitu kelompok 5, kelompok 8, dan kelompok 16 dengan 4 kendala yang dimiliki. Beberapa kendala yang dialami setiap kelompok memiliki kesamaan. Untuk itu, kendala tersebut dikelompokkan sehingga diperoleh 12 
kendala. Kendala Sahabat Sensus beserta jumlah kelompok yang mengalaminya disajikan dalam Tabel 1.

Tabel 1. Kendala Sahabat Sensus

\begin{tabular}{ccc}
\hline Variabel & $\begin{array}{c}\text { Jumlah Kelompok } \\
\text { (Kelompok) }\end{array}$ & $\begin{array}{c}\text { Persentase } \\
(\%)\end{array}$ \\
\hline K1 & 15 & 83,33 \\
K2 & 15 & 83,33 \\
K3 & 15 & 83,33 \\
\hline K4 & 13 & 72,22 \\
K5 & 13 & 72,22 \\
K6 & 12 & 66,67 \\
K7 & 4 & 22,22 \\
K8 & 3 & 16,67 \\
K9 & 3 & 16,67 \\
K10 & 3 & 16,67 \\
K11 & 1 & 5,56 \\
K12 & 1 & 5,56 \\
\hline
\end{tabular}

Dari Tabel 1, dapat dilihat bahwa terdapat enam kendala yang dialami lebih dari 50 persen kelompok Sahabat Sensus yang terdiri dari 83,33\% kelompok Sahabat Sensus mengalami kendala dalam memperoleh kepercayaan responden (K1), gangguan sinyal atau jaringan di daerah pedalaman (K2), dan server yang sering down (K3); 72,22 \% kelompok sahabat sensus menemukan kendala berupa kurangnya kepedulian responden dan NIK (K4) dan KK yang tidak sesuai (K5); serta 66,67\% kelompok sahabat sensus menemukan kendala berupa minimnya informasi yang dimiliki masyarakat mengenai SP Online 2020 (K6). Enam kendala lainnya dialami kurang dari 50\% kelompok sahabat sensus, diantaranya 22,22\% kelompok Sahabat Sensus menemukan kendala berupa data KK responden yang belum diperbaharui (K7); 16,67\% kelompok Sahabat Sensus menemukan kendala berupa responden yang tidak pandai dalam mengoperasikan smartphone (K8), hanya browser tertentu yang dapat mengakses halaman website Sensus Penduduk Online 2020 (K9), dan responden yang tidak memiliki fasilitas smartphone atau laptop (K10); dan 5,56 persen kelompok Sahabat Sensus mengalami kendala sebagai akibat dari pandemi Covid-19 (K11) dan pilihan jawaban dari website yang tidak lengkap sehingga membingungkan responden (K12).

\section{a. Analisis Faktor Kendala Sahabat Sensus}

Untuk menentukan faktor apa saja yang mempengaruhi kendala-kendala yang dialami oleh sahabat sensus tersebut dilakukan Analisis Faktor. Proses dari analisis ini bertujuan untuk menentukan hubungan antar sejumlah kendala satu dengan yang lain, sehingga jumlah kendala dapat direduksi tanpa menghilangkan informasi penting yang terkandung didalamnya. Pengolahan 12 kendala Sahabat Sensus dilakukan dengan menggunakan bantuan Software IBM SPSS Statistics 26. Hasil pengolahan data menunjukkan nilai KMO sebesar 0,520 dengan nilai Sig. 0,000. Berdasarkan nilai KMO tersebut maka variabel dan sampel sudah layak untuk dianalisis lebih lanjut. Kemudian dilanjutkan dengan menghitung nilai korelasi dari masing-masing kendala. Kendala 
dengan nilai korelasi yang kurang dari 0,5 akan dikeluarkan satu persatu dari yang terkecil dan dilakukan proses pengujian ulang sampai nilai korelasi dari kendala yang tersisa lebih dari 0,5 . Hasil akhir dari Anti Image Correlation Kendala Sahabat Sensus disajikan dalam Tabel 2.

Tabel 2. Hasil Akhir Anti Image Correlation

\begin{tabular}{cc}
\hline Kendala & Korelasi \\
\hline K1 & 0,666 \\
K2 & 0,651 \\
K3 & 0,582 \\
\hline K4 & 0,502 \\
K5 & 0,346 \\
K6 & 0,634 \\
K7 & 0,321 \\
K8 & 0,699 \\
K9 & 0,475 \\
K10 & 0,367 \\
K11 & 0,386 \\
K12 & 0,676 \\
\hline
\end{tabular}

Tabel 2 menunjukkan bahwa terdapat 5 kendala yang memiliki nilai korelasi kurang dari 0,5, diantaranya nomor NIK dan KK responden yang tidak terdaftar (K5), data KK yang belum diperbaharui (K7), hanya browser tertentu yang dapat mengakses halaman website Sensus Penduduk Online 2020 (K9), tidak semua masyarakat memiliki fasilitas smartphone atau laptop (K10), dan Sahabat Sensus tidak dapat mengajak masyarakat dalam mengisi Sensus Penduduk Online secara langsung dikarenakan pandemi Covid-19 (K11). Dari Tabel 2 juga terlihat bahwa terdapat 7 kendala yang nilai korelasi dari masing-masing kendala lebih dari 0,5. Untuk itu, ketujuh kendala tersebut dikatakan layak untuk dianalisis lebih lanjut. Langkah selanjutnya adalah menentukan faktorisasi dan rotasi dari kendala-kendala tersebut. Jumlah faktor yang terbentuk dapat dilihat dari angka eigenvalues yang memiliki nilai lebih dari satu pada scree plot-nya yang disajikan pada Gambar 3.

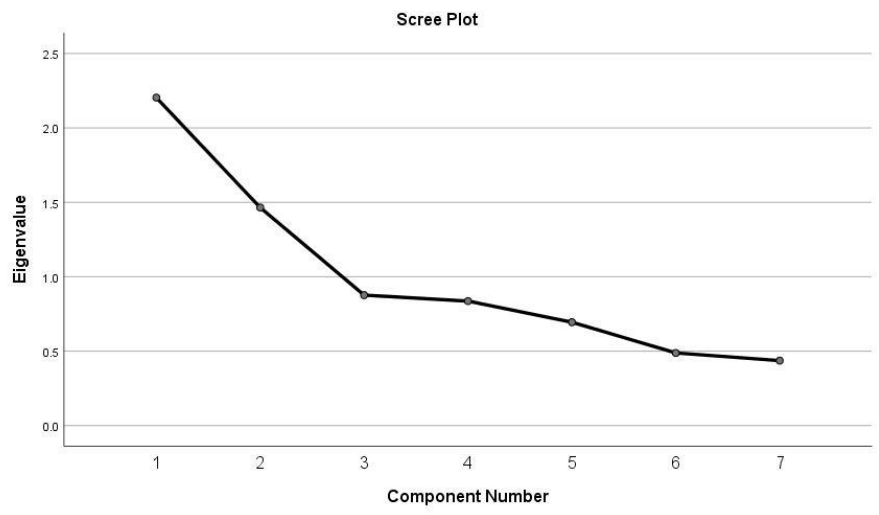

Gambar 3. Scree plot 
Berdasarkan Gambar 3, terdapat dua faktor yang terbentuk. Hal ini menunjukkan bahwa dua faktor adalah paling baik untuk meringkas ketujuh variabel tersebut. Selanjutnya dapat dilihat komponen matriks yang telah dirotasi dari masing-masing kendala yang disajikan pada Tabel 3 .

Tabel 3. Komponen Matriks yang Telah Dirotasi

\begin{tabular}{ccc}
\hline Kendala & \multicolumn{2}{c}{ Komponen } \\
\cline { 2 - 3 } & 0,816 & 0,079 \\
K1 & 0,520 & 0,440 \\
K2 & $-0,183$ & 0,644 \\
K3 & $-0,041$ & 0,792 \\
K4 & 0,334 & 0,515 \\
K6 & 0,788 & $-0,011$ \\
K8 & 0,660 & $-0,150$ \\
\hline
\end{tabular}

Berdasarkan Tabel 3, komponen matriks yang telah dirotasi menunjukkan distribusi yang lebih jelas dan nyata karena nilai korelasi tertingginya semuanya lebih dari 0,5. Dengan demikian, ketujuh variabel tersebut telah direduksi menjadi hanya terdiri dari dua faktor. Faktor 1 terdiri dari ketidakpercayaan responden terhadap Sensus Penduduk Online 2020 (K1), gangguan jaringan atau sinyal di daerah pedalaman yang dialami responden dalam mengisi Sensus Penduduk Online 2020 (K2), pilihan jawaban yang tidak lengkap sehingga membingungkan responden (K12), dan ketidakpandaian responden dalam mengoperasikan smartphone (K8), sedangkan faktor 2 terdiri dari variabel kurangnya informasi yang diperoleh masyarakat mengenai Sensus Penduduk Online 2020 (K6), server Sensus Penduduk Online 2020 sering down (K3), dan kurangnya kepedulian responden terhadap Sensus Penduduk Online 2020 (K4).

\section{b. Analisis Chi Kuadrat Kendala Sahabat Sensus}

Kendala yang dialami Sahabat Sensus dikelompokkan menjadi tiga bagian, yaitu:

(i) Tidak terdapat kendala yang ditemukan Sahabat Sensus;

(ii) Kendala yang diluar kendali Sahabat Sensus yang terdiri dari kendala gangguan jaringan, Server yang sering down, hanya browser tertentu yang dapat mengakses halaman website Sensus Penduduk, dan tidak semua masyarakat memiliki fasilitas Smartphone atau Laptop;

(iii) Kendala yang terjadi dalam kendali Sahabat Sensus, diantaranya ketidakpercayaan responden, kurangnya kepedulian responden, nomor NIK dan KK yang belum terdaftar, kurangnya informasi yang diperoleh masyarakat, data KK yang belum diperbaharui, ketidakpandaian responden dalam mengoperasikan Smartphone, tidak dapat mengajak masyarakat berpartisipasi secara langsung dikarenakan pandemi Covid-19, dan pilihan jawaban yang tidak lengkap.

Hasil dari pengelompokkan tersebut disajikan dalam Tabel 4. 
Tabel 4. Jumlah Sahabat Sensus Berdasarkan Jenis Kelamin dan Kendala

\begin{tabular}{|c|c|c|c|c|}
\hline \multirow{2}{*}{ Jenis Kelamin } & \multicolumn{3}{|c|}{ Kendala } & \multirow{2}{*}{ Total } \\
\hline & Tidak Ada & Luar Kendali & Dalam Kendali & \\
\hline Laki-Laki & 15 & 9 & 4 & 28 \\
\hline Perempuan & 52 & 17 & 5 & 74 \\
\hline Total & 67 & 26 & 9 & 102 \\
\hline
\end{tabular}

Dari Tabel 4, terlihat bahwa Sahabat Sensus berjenis kelamin laki-laki berjumlah 28 orang, dimana 15 orang tidak memiliki kendala, 9 orang mengalami kendala diluar kendali, dan 4 orang mengalami kendala dalam kendali. Sedangkan Sahabat Sensus yang berjenis kelamin perempuan berjumlah 74 orang dengan 52 orang tidak memiliki kendala, 17 orang mengalami kendala diluar kendali, dan 5 orang mengalami kendala dalam kendali.

Langkah selanjutnya yaitu, 12 kendala yang ditemukan dianalisis menggunakan Analisis Chi Kuadrat untuk mengetahui apakah jenis kelamin Sahabat Sensus mempengaruhi kendala yang dialami Sahabat Sensus dengan hipotesis sebagai berikut:

$\mathrm{H}_{0}$ : Tidak terdapat pengaruh antara variabel jenis kelamin terhadap kendala yang dialami Sahabat Sensus pada Sensus Penduduk 2020.

$\mathrm{H}_{1}$ : Terdapat pengaruh antara variabel jenis kelamin terhadap kendala yang dialami Sahabat Sensus pada Sensus Penduduk 2020.

Dengan menggunakan Chi Kuadrat, hasil analisis pengaruh jenis kelamin Sahabat Sensus menunjukkan nilai Chi-Square sebesar 2,837 dengan derat bebas yaitu 2 dan nilai sig. 0,242. Dari hasil tersebut dapat disimpulkan bahwa $\mathrm{H}_{0}$ diterima. Artinya, tidak terdapat pengaruh antara variabel jenis kelamin terhadap kendala yang dialami Sahabat Sensus pada Sensus Penduduk 2020.

\section{SIMPULAN} berikut:

Berdasarkan analisis yang digunakan dalam penelitian ini maka diperoleh hasil sebagai

a. Media sosial yang digunakan dalam kegiatan publikasi Sensus Penduduk Online 2020 adalah Instagram, WhatsApp, Facebook, Telegram, Twitter, dan Sestyc. Media sosial Instagram, WhatsApp, dan Facebook yang sedang popular di kalangan masyarakat lebih banyak digunakan dalam kegiatan publikasi dibanding Telegram, Twitter, dan Sestyc.

b. Kendala yang dialami Sahabat Sensus dikelompokkan menjadi 12 kendala. Dari kendalakendala tersebut, terdapat 6 kendala yang dialami lebih dari 50\% dari kelompok Sahabat Sensus, antara lain $83,33 \%$ kelompok Sahabat Sensus mengalami kendala dalam memperoleh kepercayaan responden, 83,3\% gangguan sinyal atau jaringan di daerah pedalaman, 83,3\% server yang sering down; 72,22\% kelompok Sahabat Sensus menemukan kendala berupa kurangnya kepedulian responden, $72,2 \%$ nomor NIK dan KK yang tidak sesuai; serta 66,67\% kelompok Sahabat Sensus Penduduk Online 2020.

c. Faktor kendala yang terbentuk dari proses analisis faktor menghasilkan dua faktor. Faktor 1 terdiri atas ketidakpercayaan responden terhadap Sensus Penduduk Online 2020, gangguan jaringan atau sinyal di daerah pedalaman yang dialami responden dalam mengisi Sensus Penduduk Online 2020, pilihan jawaban yang tidak lengkap sehingga membingungkan responden, dan ketidakpandaian responden dalam mengoperasikan smartphone. Faktor 2 
terdiri atas variabel kurangnya informasi yang diperoleh masyarakat mengenai Sensus Penduduk Online 2020, server Sensus Penduduk Online 2020 sering down, dan kurangnya kepedulian responden terhadap Sensus Penduduk Online 2020.

d. Dari hasil pengujian dengan menggunakan Chi Kuadrat diperoleh tidak terdapat pengaruh antara variabel jenis kelamin terhadap kendala yang dialami Sahabat Sensus pada Sensus Penduduk 2020.

\section{REFERENSI}

BPS. Sensus Penduduk 2020 [Internet]. 2020 [cited 2020 May 2]. Available from: https://www.bps.go.id/sp2020/.

Fitriatien, Sri Rahmawati. (2017). Pengolahan Dataset Awal Minat Belajar Mahasiswa Melalui Algoritma Principle Component Analysis (PCA). Jurnal SENAMAS, 2017. 2017;208-215.

Hasaniyah, Alfi. (2015). Uji Beda Para Ibu Rumah Tangga Menggunakan Bahan Bakar Mlnyak Tanah dan Gas Elpiji di Desa Pandan Kecamatan Galis. Jurnal Makro Manajemen, 2015;2(20);49-60.

Ismail, Kamarul, Siti Naeilah Ibrahim \& Ruslan Rainis. (2013). Pembangunan Sistem Geodemografi di Pulau Pinang: Proses Pemilihan Variabel dengan Menggunakan Analisis Komponen Utama (PCA). Jurnal Perspektif: Jurnal Sains Sosial dan Kemanusiaan, 2013;5(1); 83-96.

Ismowati, M., \& Sulatifah. (2019). Analisis Faktor Kualitas Pelayanan di Kelurahan Jatikarya Kecamatan Jatisampurna Kota Bekasi. Jurnal Transparansi, 2(1), 97-108.

Liberna, Hawa. (2018). Hubungan Gaya Belajar Visual dan Kecemasan Diri terhadap Pemahaman Konsep Matematika Siswa Kelas X SMK Negeri 41 Jakarta. Jurnal JNPM (Jurnal Nasional Pendidikan Matematika), 2018;2(1);98-108.

Maghfira R., \& Ridho F. (2021). Social Sensing Sensus Penduduk 2020 Pada Jejaring Sosial Twitter. Prosiding Seminar Nasional Official Statistics 2020, Jakarta: 23-24 September 2020: Politeknik Statistika STIS.

Peraturan Presiden Republik Indonesia Nomor 39 Tahun 2019 Satu Data Indonesia. 17 Juni 2019. Lembaran Negara Republik Indonesia Tahun 2019 Nomor 112. Jakarta.

Rahayu, Gusni \& Mustakim. (2017). Principal Component Analysis untuk Dimensi Reduksi Data Clustering Sebagai Pemetaan Persentase Sertifikasi Guru di Indonesia Seminar Nasional Teknologi Informasi, Komunikasi dan Industri (SNTIKI), Riau: 18-19 Mei 2017: UIN Sultan Syarif Kasim.

Rahman, Arief Aulia \& Fauziana. (2018). Analisis Faktor Eksternal Penyebab Kesulitan Beajar Siswa SMP Melalui Pembeajaran Scientific Approach. Jurnal MAJU, 2018;5(2);29-40

Suharno CF, Fauzi MA, \& Perdana RS. (2017). Klasifikasi Teks Bahasa Indonesia pada Dokumen Pengaduan Sambat Online Menggunakan Metode Chi-Square. Syst Inf Syst Informatics J. 2017;3(1);25-32.

Sugiyono. (2014). Statistika untuk Penelitian. Alfabeta, Bandung. 
Syahrial, $d k k$. (2018). Faktor yang Mempengaruhi Kesehatan Populasi Rhizophora apiculata Berdasarkan Karakteristik Lingkungan pada Kawasan Industri Perminyakan dan Non Kawasan Industri di Provinsi Riau Menggunakan Analisis Komponen Utama (PCA). Jurnal Enggano, 2018;3(2);228-240.

Undang-Undang Nomor 16 Tahun 1997 Statistik, 19 Mei 1997. Lembaran Negara Republik Indonesia Tahun 1997 Nomor 3. Jakarta.

Upomo, T C. \& Rini K. (2016). Pemilihan Distribusi Probabilitas pada Analisa Hujan dengan Metode Goodness of Fit Test. Jurnal Teknik Sipil dan Perencanaan, 2016;18(2);139-148. 